\title{
Coronary Heart Disease Mortality Among Men Aged 35-44 Years by Prefecture in Japan in 1995-1999 Compared With That Among White Men Aged 35-44 by State in the United States in 1995-1998 Vital Statistics Data in Recent Birth Cohorts
}

\author{
Akira Sekikawa, MD, PhD; Toshihiko Satoh, MD*; Takehito Hayakawa, $\mathrm{PhD}$ **; \\ Hirotsugu Ueshima, MD**; Lewis H. Kuller, MD
}

\begin{abstract}
The levels of risk factors for coronary heart disease (CHD) in men in the post World War II (WWII) birth cohort are almost similar between Japan and the USA, except for the considerably higher prevalence of cigarette smoking in Japan and the much higher prevalence of obesity in the USA. The present study evaluated the CHD mortality among men in the post WWII birth cohort by prefecture in Japan in 1995-1999 and then compared the data with those for white men in different states in the USA. There was a greater than 2-fold difference in CHD mortality among men aged 35-44 by prefecture in Japan: 5.3/100,000 in Kumamoto vs 12.6/100,000 in Tochigi. CHD mortality among men aged 35-44 in the top 3 prefectures in Japan is about half that of white men in the USA and is similar to that of white men in the lowest 3 states. The much lower CHD mortality in Japan does not appear to be caused by differences in the classification of causes of death and the results suggest that there may be strong and important protective factors that reduce the risk of CHD in Japan. (Jpn Circ J 2001; 65: 887-892)
\end{abstract}

Key Words: Coronary heart disease; Japan; Mortality; Post Word War II birth cohort; USA

$\mathbf{S}$ ince World War II (WWII), there have been important changes in lifestyle that have had a major impact on the risk for coronary heart disease (CHD), such as the decline in total cholesterol levels, improved treatment of hypertension, and the decline in the prevalence of cigarette smoking, in the United States of America (US) and many other Western countries ${ }^{1-3}$ At the same time, many non-Western countries, including Japan, have been exposed to the Western lifestyle ${ }^{4}$ and data from national sample surveys in the US and Japan clearly demonstrate that the differences in the levels of cholesterol and blood pressure between the 2 countries have became much smaller during the past decades:-10 In fact, among men in the post WWII birth cohort, the risk factor profiles for CHD (levels of total cholesterol, systolic and diastolic blood pressure) are very similar between white men in the US and men in Japan, except for the considerably higher prevalence of cigarette smoking in Japan and the much higher prevalence of obesity in the US!1 In 1988-1994 in the US the mean level of total cholesterol among men aged 20-34 and 35-44 years was $186 \mathrm{mg} / \mathrm{dl}$ and $206 \mathrm{mg} / \mathrm{dl}$, respectively 5 and for

(Received November 24, 2000; revised manuscript received July 3, 2001; accepted July 10, 2001)

Department of Epidemiology, Graduate School of Public Health, University of Pittsburgh, Pittsburgh, USA, *Global Programme on Evidence for Health Policy/Epidemiology and Burden of Disease, World Health Organization, Geneva, Switzerland and **Department of Health Science, Shiga University of Medical Science, Shiga, Japan Mailing address: Akira Sekikawa, MD, PhD, Department of Epidemiology, Graduate School of Public Health, University of Pittsburgh, 3512 Fifth Avenue, Pittsburgh PA 15213, USA. E-mail: akira@pitt.edu men aged 30-39 years in Japan in 1989 it was $201 \mathrm{mg} / \mathrm{dl}$. The mean systolic and diastolic blood pressures among white men in the US aged 30-39 years in 1988-1991 were $119 \mathrm{mmHg}$ and $77 \mathrm{mmHg}$, respectively, and for similar aged Japanese men in 1989 they were $127 \mathrm{mmHg}$ and 77 $\mathrm{mmHg}$, respectively. The prevalence of cigarette smoking among white men in the US aged 25-34 and 35-44 years in 1990 was $32 \%$ and $34 \%$, respectively 5 whereas it was $65 \% 10$ among Japanese men aged 30-39 years in 1989. In 1989 , about $15 \%$ of men aged $20-29$, and $20 \%$ of men aged 30-39 years in Japan were overweight (body mass index $\geq 25.0)$ 9 whereas in the US in 1988-1994, the proportions were $47.5 \%$ of men aged $20-34$ and $66.5 \%$ of men aged 35-44 years 5

Nationwide autopsy studies in Japan indicate that extent and severity of atherosclerosis in the coronary arteries of young men became more extensive in the 1990s, ${ }^{12,13}$ and the surface involvement of fatty streaks and fibrous plaques was comparable with that among young white men in the US $!^{14}$ There are limitations in comparing the results because almost all the cases examined in Japan died of non-external causes whereas the study in the US examined cases of death from external causes, and the data were not drawn from nationally representative samples. It is notable, however, that the surface involvement (fatty streaks plus fibrous plaques) among men in their 20s in Japan in 1991-1995 is more extensive than among comparable white men in the US in 1987-1994!3,14

Comparing the CHD mortality rate among men in the post WWII birth cohort (ie, those aged 35-44 years) may better reflect recent changes in risk factors than comparing the age-adjusted rate or rate among men in an older age 
group because alterations in risk factors would emerge more rapidly in younger groups, as has been observed in the US and other countries ${ }^{15,16}$ Also, taking into account the opposite direction of the changes in risk factors for CHD between the US and Japan, comparing the age-adjusted mortality may be misleading because of the cohort effect.

It is possible that the CHD mortality in Japan has been underestimated because heart attack may be reported as acute heart failure and the cause of death may be then misclassified as heart failure! ${ }^{17}$ The Ministry of Health and Welfare in Japan added the instruction for death certificate

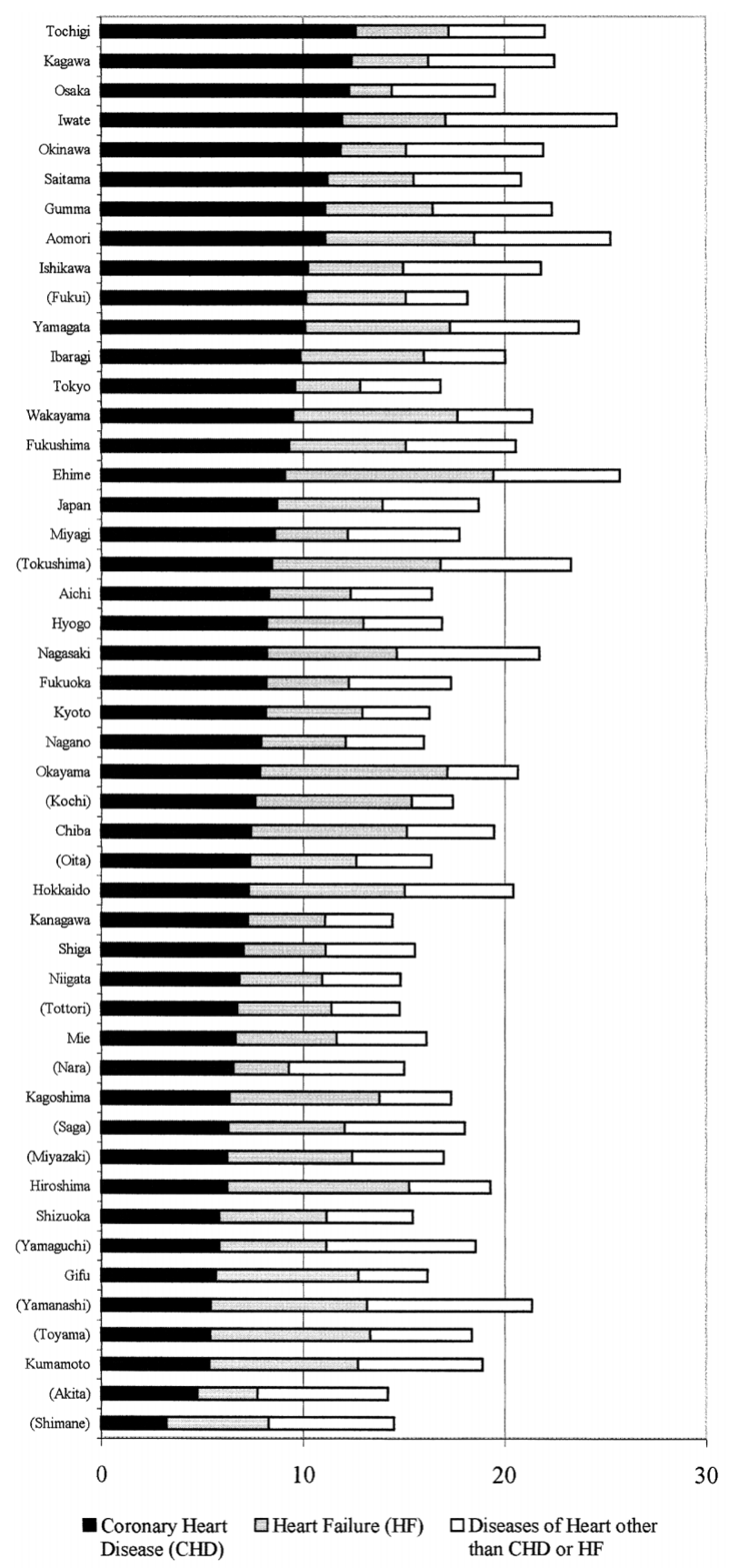

Fig 1. Mortality from coronary heart disease (CHD), diseases of heart, and heart failure $(/ 100,000)$ among men aged 35-44 years in 1995-1999 by prefecture in Japan. Values in parenthesies indicates that the number of CHD deaths in that prefecture was small and the CHD mortality data could be unreliable. coding 'Do not put heart failure as a cause of death when it is a manifestation of the terminal state of disease' when the 10th revision of the International Classification of Diseases (ICD-10) was introduced in 1995. As a result, from 19901992 to $1995-1997$ the mortality among men aged 35-44 years from heart failure decreased by $68 \%$ and that from CHD rose by $65 \%$ ! 8

We recently reported a 3 -fold difference in the CHD mortality among white men aged 35-44 years by state in the US $1{ }^{19}$ Mortality in the top 3 states was almost as high as that in Poland, which has one of the highest rates in Europe, whereas mortality in the lowest 3 states in the US was less than that in France, which has one of the lowest rates in Europe and the world.

We hypothesized that there would be a 2- to 3-fold difference in mortality from CHD among men aged 35-44 years by prefecture in Japan, and that the CHD mortality in the top prefecture would be much higher than that among white men in the lowest state in the US. We investigated the mortality from CHD, and from the subcategories of heart diseases, among Japanese men, and compared the data with those for similar aged white men in some states of the US and in some other countries.

\section{Methods}

The number of deaths by sex, age group, prefecture, and ICD code from 1995 to 1999 was obtained from the Vital Statistics Division, Statistics and Information Department, Ministry of Health, Labor, and Welfare in Japan. The population by sex, age group, and prefecture from 1995 to 1999 was obtained from the Statistics Bureau and Statistics Center in Japan. Mortality data in the US from 1995 to 1998 (the latest available data) were obtained from the CDC Wonder database (http://wonder.cdc.gov/), maintained by the Centers for Disease Control and Prevention, which enabled data on mortality to be extracted by age group, race, sex, state, underlying cause of death by the ICD-9 code, etc. The mortality data by country, age group, sex, year, ICD code, etc were obtained from the World Health Organization Statistical Information System (WHOSIS; http://www.who.int/whosis/), maintained by the World Health Organization (WHO). Countries selected were Australia, Canada, Finland, France, Greece, Hungary, Poland, and the United Kingdom (UK). Data were available for most of the countries for the year of 1996 or 1997 and by ICD-9 code.

For CHD, codes I20-25 in ICD-10 and codes 410-414 in ICD-9 were used. For diseases of heart, codes I01-51 in ICD-10 and codes 390-429 in ICD-9 were used. Diseases of heart is a cumulative grouping recommended by the WHO for the tabulation of mortality data and is much more reliable in comparing mortality among industrialized countries than CHD because of the heterogeneity of recording the cause-of-death. ${ }^{2}$ For heart failure, code I50 in ICD-10 and code 428 in ICD- 9 were used.

\section{Results}

Mortality rates from CHD, heart failure, and diseases of heart among Japanese men aged 35-44 years from 1995 to 1999 were 8.7/100,000, 5.2/100,000 and 18.7/100,000, respectively. Fig 1 shows the variation in mortality from these 3 conditions by prefecture. In 13 prefectures, the number of deaths from CHD was small and the data could 


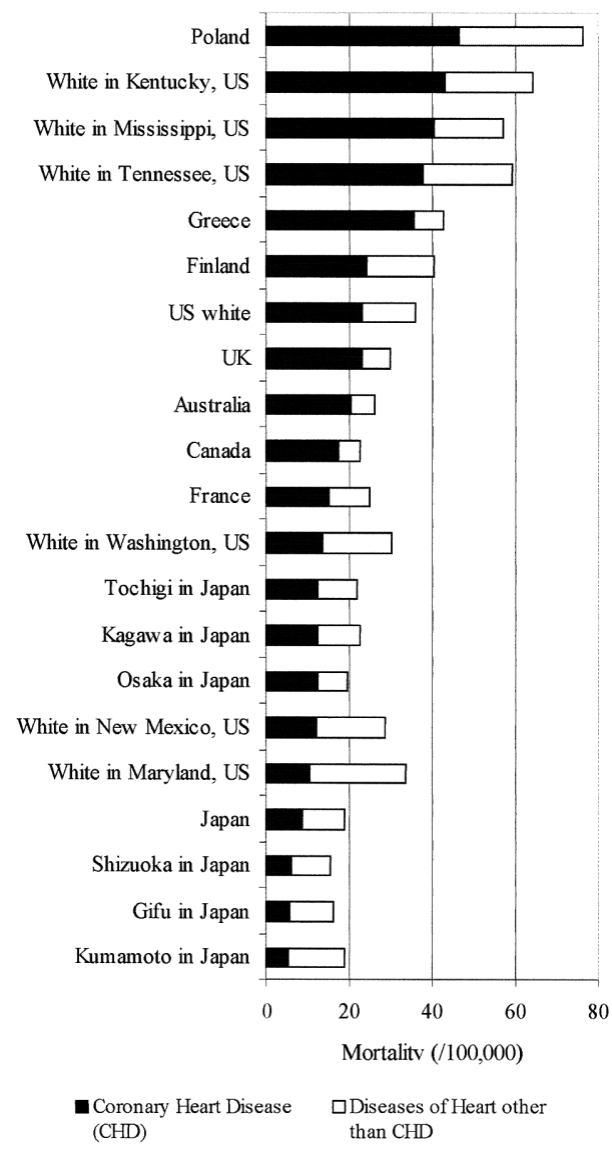

Fig 2. Mortality from coronary heart disease (CHD) and diseases of heart among men aged 35-44 years in the highest and lowest 3 prefectures in Japan in 1995-1999, among white men aged 35-44 years in 1995-1998 in the highest and lowest 3 states in the United States, and among men aged 35-44 years in 1994 in some other countries. Mortality rates from CHD and diseases of heart in Hungary in 1998 were 82.6/100,000 and 116.4/100,000, respectively.

be unreliable, but even after excluding these prefectures, there was a greater than 2-fold difference in mortality from CHD: $5.3 / 100,000$ in Kumamoto vs $12.6 / 100,000$ in Tochigi. There was an almost 2-fold difference in mortality from diseases of heart: 14.4/100,000 in Kanagawa vs 25.7/100,000 in Ehime. The proportion of mortality from diseases of heart in categories other than CHD among Japanese men aged 35-44 years was $53.5 \%$, and by prefecture, it ranged from $27.0 \%$ in Osaka to $71.8 \%$ in Kumamoto. Mortality from heart failure ranged from 2.1/100,000 in Osaka to $10.3 / 100,000$ in Ehime. The proportion of mortality from heart failure in mortality from diseases of heart (mortality from heart failure/mortality from diseases of heart) among Japanese men aged 35-44 years was 27.7\% and by prefecture it ranged from $10.8 \%$ in Osaka to $46.7 \%$ in Hiroshima.

Fig 2 shows the mortality from CHD and diseases of heart among 35-44-year-old Japanese men and white men in the US and other countries, in addition to the highest and lowest 3 prefectures in Japan and the highest and lowest 3 states in the US. Mortality from CHD among Japanese men aged 35-44 years in the lowest 3 prefectures was much lower than among white men in the lowest 3 states in the US, whereas in the top 3 prefectures it was similar to that among white men in the lowest 3 states: 12.6/100,000 in

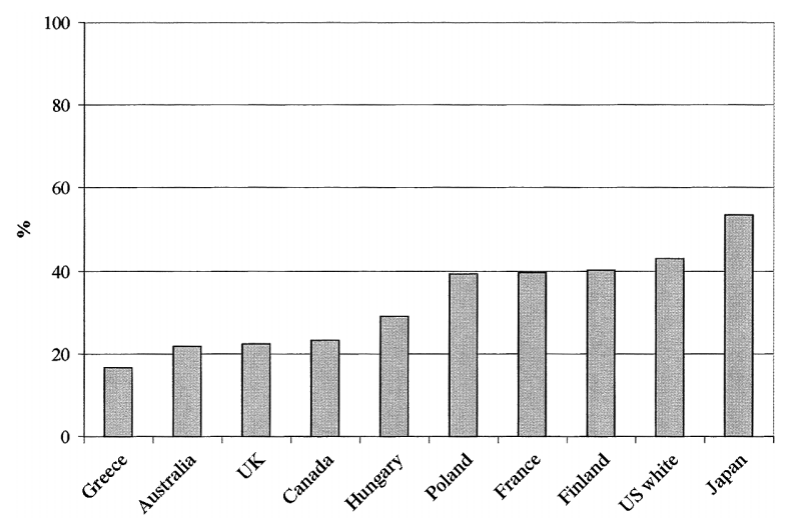

Fig 3. Proportion by country of mortality assigned to other than coronary heart disease (CHD) in the category of diseases of heart.

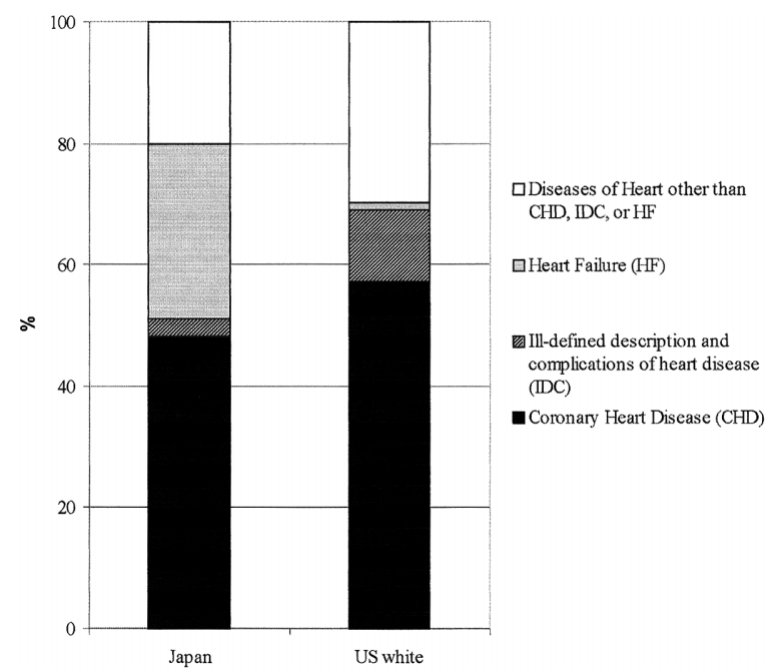

Fig 4. Proportion of mortality from coronary heart disease (CHD), ill-defined description and complications of heart (IDC), heart failure (HF), and others in the category of diseases of heart between men aged 35-44 years in Japan in 1995-1999 and white men in the US in 1995-1998.

Tochigi, 12.4/100,000 In Kagawa, and 12.2/100,000 in Osaka, vs 13.7/100,000 in Washington, 12.0/00,000 in New Mexico, and 10.4/100,000 in Maryland. Mortality from CHD among Japanese men aged 35-44 years in the highest 3 prefectures in Japan was still lower than in France, where the mortality from CHD is one of the lowest among industrialized countries $(15.1 / 100,000)$, and mortality from diseases of heart in this cohort in the highest 3 prefectures was much lower than that among white men in the lowest 3 states in the US: $22.0 / 100,000$ in Tochigi, $22.5 / 100,000$ in Kagawa, and 19.5/100,000 in Osaka, vs 33.6/100,000 in Maryland, 30.0/100,000 in Washington, and 28.5/100,000 in New Mexico. Mortality from diseases of heart in the highest 3 prefectures in Japan was lower than in France (25.1/100,000).

Fig 3 shows the proportion of mortality from diseases of heart in categories other than CHD in Japan and the other countries. The proportion ranged from $16.7 \%$ in Greece to $53.5 \%$ in Japan. Less than one-fifth of deaths from diseases of heart among men aged 35-44 years in Greece were not $\mathrm{CHD}$ whereas more than half of the deaths from diseases of 
heart among Japanese men were diagnosed as other than CHD.

Fig 4 shows the proportion of mortality from CHD, illdefined descriptions and complications of heart disease (IDC) (ICD-10 code: I-51, ICD-9 code: 429), heart failure (HF), and diseases of heart other than CHD, IDC or HF among men aged 35-44 years in Japan from 1995 to 1999 and white men aged 35-44 years in the US from 1995 to 1998. More than a quarter of deaths in diseases of heart among the Japanese men were coded as heart failure, which represented less than $2 \%$ among the white men in the US. Approximately $12 \%$ of diseases of heart among US white men were coded as ill-defined descriptions and complications of heart disease, whereas this proportion was very small in Japan. Most of the deaths in the ill-defined descriptions and complications of heart disease $(\approx 80 \%)$ among white men in the US were coded as arteriosclerotic cardiovascular disease (ASCVD; ICD-9 code 429.2).

\section{Discussion}

We observed a 2-fold difference in mortality from CHD and diseases of heart by prefecture among Japanese men aged 35-44 years. We had previously reported that in the US, differences by state in CHD mortality among white men aged 35-44 years were most likely attributable to differences in levels of risk factors, rather than to differences in medical services because most of the CHD deaths in this age group were sudden and not in hospital. ${ }^{19}$ Unfortunately, there are no age- and sex-specific data on the risk factors for CHD by prefecture or by state and further investigations are needed to elucidate the cause of the variations in CHD mortality.

In spite of the similar levels of risk factors for CHD between Japan and the US for men in the post WWII birth cohort, the mortality from CHD among Japanese men in the top 3 prefectures was much lower than for white men in the US and was similar to that among white men in the lowest 3 states. The mortality from diseases of heart in the top 3 prefecture was also much lower than that in the lowest 3 states in the US.

We compared the proportion of mortality from disease of heart other than CHD and found that the proportion was highest among the men in Japan, followed by white men in the US, suggesting that the mortality from CHD is underestimated in both countries. We further examined the mortality from subcategories of diseases of heart among these men and found that in the US, approximately $10 \%$ of the deaths in the diseases of heart were coded by coroners as ASCVD (ICD-9 code: 429.2) to denote CHD that falls somewhat short of definitive evidence of a myocardial infarction, but was separate from the rest of codes for CHD in ICD-920 Such deaths were coded 412.4 under the ICD-8 and, therefore, in the US, mortality from ASCVD should be added to mortality from CHD. This proportion was negligible among the Japanese men aged 35-44 years. The proportion of mortality from heart failure in this age group in Japan was still much higher than for white men in the US, in whom death from heart failure was rarely coded, even after the instruction by the Ministry of Health in Japan in 1995. It is likely that the mortality from CHD among these men in Japan is still underestimated.

The death certificates of cases of cardiovascular diseases in Japan have been validated with the WHO MONICA criteria21 After the re-evaluation, however, a substantial proportion were categorized as either sudden death of unknown origin or insufficient data. These studies $22-25$ examined people aged 15-24 years, or 25-74 years and the number of deaths among men aged 35-44 years is too small to draw any inferences on the post WWII birth cohort. In addition, these studies were conducted before 1995, when the Ministry of Health and Welfare added the instruction for death certificates concerning heart failure. Baba et al evaluated the death certificates of cases of CHD, heart failure, other heart diseases, stroke, and others, which may contain CHD deaths, among people aged 25-74 years in Suita, Japan from 1984 to 1986 using clinical and police records ${ }^{22}$ and found that approximately $4 \%$ of cases of stroke (ICD-9 codes: 430-438) by death certificate were actually from CHD after re-evaluation. They concluded that CHD deaths could be underestimated by $11 \%$. However, approximately $30 \%$ were classified as either sudden death of unknown origin or insufficient data or were not re-evaluated. Naruse et al evaluated the death certificates of cases of CHD and heart failure among people aged 15-74 years in rural areas in Japan from 1987 to 1990 using clinical records ${ }^{23}$ and concluded that CHD deaths could be underestimated by $7.7 \%$, although approximately $35 \%$ were classified as insufficient data after the evaluation. In the Oita Cardiac Death Survey (OCDS), Saito et al evaluated the death certificates of cases of CHD, heart failure, other heart diseases and others, which may contain CHD deaths, among people aged 25-74 years in Oita, Japan from 1992 to 1993 using clinical and police records 24 and they concluded that the CHD deaths could be underestimated by $30 \%$; approximately $30 \%$ were classified as either sudden death of unknown origin or insufficient data after the evaluation. Recently, Saito et al compared the mortality from CHD among men and women aged 35-74 years in the OCDS with the data from the Atherosclerosis Risk in Communities Study 25 and reported that when sudden deaths were counted as CHD deaths, the differences in mortality from CHD were not as great as suggested by vital statistics, and the ratio of mortality from CHD among men (US/Japan) fell from 5.9 to 4.7 .

A much higher incidence rate of type 1 diabetes mellitus (IDDM) and CHD as cause of death in the US account to some extent for the difference. Traven et al investigated CHD mortality and sudden death among people aged 35-44 years in Allegheny County, USA ${ }^{26}$ and of the CHD deaths during 1984 to $1989,20 \%$ had IDDM. The incidence of IDDM among children aged 0-14 years in Japan has been reported as $1.82 / 100,000{ }^{27}$ which is one-quarter to one-fifth as low as that in the US 28 The Diabetes Epidemiology Research International Mortality Group reported that cardiovascular/cerebrovascular-disease-specific mortality among patients with IDDM comprised only $2 \%$ of all deaths in Japan, compared with $10 \%$ in the US ${ }^{29}$

Even when these factors are taken into account, however, mortality from CHD among men aged 35-44 years in Japan is still much lower than that among comparable white men in the US, and in the top prefecture in Japan the rate is similar to that of white men in the lowest state in the US. Assuming that $20 \%$ of CHD deaths (ICD-9 codes: 410-414, 429.2) among white men in the US are caused by IDDM and thus excluded from CHD for the comparison, the mortality from CHD among white men in the US would be 21.6/100,000. Assuming that all the cases of CHD (ICD-10 codes: I20-25) on death certificate are true cases of $\mathrm{CHD}$, and that $50 \%$ of cases from heart failure (ICD-10 
code: I50) on death certificate are in fact from CHD, and $5 \%$ of cases of stroke (ICD-10 codes: I60-69) are from CHD, the estimated CHD among men aged 35-44 years in Japan would be still 12.0/100,000. When the same assumptions were applied to prefecture-specific mortality from 1995 to 1999 and to state-specific mortality from 1995 to 1998, the estimated CHD mortality in the top 3 prefectures in Japan is $16.0 / 100,000$ to $16.8 / 100,000$, whereas that in the lowest 3 states is $14.4 / 100,000$ to $15.2 / 100,000$.

\section{Study Limitations}

First, the mortality data are based only on vital statistics in both Japan and the US. Second, the assumptions are not based on mortality validation studies in men aged 35-44 years, other than the studies in Allegheny County, USA. Third, diagnostic practice is likely to differ not only by country, but also by region within a country (ie, by prefecture in Japan, and by state in the US).

Even with these limitations, this study is likely to overestimate the true rate of CHD mortality in Japan because all the cases of CHD by death certificate were assumed to be true cases of $\mathrm{CHD}$, which is very unlikely? ${ }^{2-25} \mathrm{We}$ also believe that the CHD mortality in the US is likely to be overestimated because we assumed that $20 \%$ of CHD deaths were due to IDDM and were thus excluded from comparison. This figure $(20 \%)$ was based on the mortality validation study carried out in Allegheny County, which has one of the highest incidence rates of IDDM within the US? 8

The present data imply that among the post WWII birth cohort of men aged 35-44 years, mortality from CHD is still much higher in white men in the US than that among men in Japan, in spite of the very similar traditional risk factor profiles, other than the considerably higher prevalence of cigarette smoking in Japan and the much higher prevalence of obesity in the US. If true, differences in genetic factors would be unlikely to explain the differences in mortality because studies of Japanese male migrants to the US clearly illustrate an increase in the morbidity and mortality from CHD?0-32 There may be several reasons for the much lower CHD mortality among the men in Japan: (1) higher levels of high density lipoprotein cholesterol;33-35 (2) higher consumption of soy products; ${ }^{36}$ (3) higher polyunsaturated/saturated fat ratio;37 (4) higher alcohol consumption; 38 (5) higher fish consumption;39,40 (6) a time lag between the increase in levels of cholesterol and the increase in mortality from CHD; 41 and others. ${ }^{4-44}$ The identification of these factors would be extremely valuable for the prevention of CHD, so there is a clear need for monitoring trends in morbidity and mortality from CHD and atherosclerosis, as well as the trends in risk factors among men in the post WWII birth cohort.

\section{References}

1. Manson JE, Gaziano M, Ridker PM, Hennekins CH: Myocardial Infarction: Epidemiologic Overview. In: Manson JE, Ridker PM, Gaziano JM, Hennekens CH, editors. Prevention of myocardial infarction. New York: Oxford University Press, 1996: 3-31

2. Goldman L, Cook EF: The decline in ischemic heart disease mortality rates. Ann Intern Med 1984; 101: 825-836

3. World Health Organization: Health across the life span. In: The world health report 1998: Life in the 21st century. Geneva: WHO, 1998: $61-112$

4. Ministry of Health and Welfare: National nutrition survey 1998. Tokyo: Daiichi Shuppan Publisher, 2000 (in Japanese)

5. MacKay AP, Fingerhut LA, Duran CR: Adolescent health chartbook: Health, United States, 2000. Hyattsville, Maryland: National Center for Health Statistics, 2000

6. Ministry of Health and Welfare: National nutrition survey 1989. Tokyo: Daiichi Shuppan Publisher, 1991 (in Japanese)

7. Ministry of Health and Welfare: The third national survey of circulatory disorders 1980. Tokyo: Japan Heart Foundation, 1983 (in Japanese)

8. Burt VL, Cutler JA, Higgins M, Horan MJ, Labarthe D, Whelton P, et al: Trends in the prevalence, awareness, treatment, and control of hypertension in the adult US population: Data from the Health Examination Surveys, 1960 to 1991. Hypertension 1995; 26: 60-69

9. Okayama A, Ueshima H, Marmot MG, Nakamura M, Kita Y, Yamakawa M: Changes in total serum cholesterol and other risk factors for cardiovascular disease in Japan, 1980-1989. Int J Epidemiol 1993; 22: 1038 - 1047

10. Ministry of Health and Welfare: National nutrition survey 1998. Tokyo, Daiichi Shuppan Publisher, 2000 (in Japanese)

11. Sekikawa A, Kuller LH, Ueshima H, Park JE, Suh I, Jee SH, et al: Trends of mortality from coronary heart disease in the post World War II birth cohorts aged 35-44 in men in Japan, South Korea, and Taiwan, and a comparison with the United States. Int J Epidemol 1999; 28: $1044-1049$

12. Tanaka K, Masuda J, Imamura T, Sueish K, Nakashima T, Sakurai I, et al: A nation-wide study of atherosclerosis in infants, children and young adults in Japan. Atherosclerosis 1988; 72: 143-156

13. Imakita M, Yutani C, Sakurai I, Subiyoshi A, Watanabe T, Mitsumata $\mathrm{M}$, et al: The second nationwide study of atherosclerosis in infants, children, and young adults in Japan. Ann NY Acad Sci 2000; 902: 364-368

14. Strong JP, Malcom GR, McMahan CA, Tracy RE, Newman WP III, Herderick EE, et al for the Patholobiological Determinants of Ahterosclerosis in Youth Research Group: Prevalence and extent of atherosclerosis in adolescents and young adults. JAMA 1999; 281: $727-735$

15. Uemura K, Pissa Z: Trends in cardiovascular disease mortality in industrialized countries since 1950. World Health Stat Q 1988; 41: $155-178$

16. Levy RI: The decline in cardiovascular disease mortality. Апnи Rev Public Health 1981; 2: 49-70

17. Koga Y, Hashimoto R, Adachi H, Tsuruta M, Tashiro H, Toshima H: Recent trends in cardiovascular disease and risk factors in the seven countries study: Japan. In: Toshima H, Koga Y, Blackburn H, Keys A, editors. Lessons for science from the seven countries study. Tokyo: Springer-Verlag, 1994: 63-74

18. Sekikawa A, Ueshima H, Satoh T, Kuller LH: Rise in mortality from coronary heart disease among post World War birth cohorts in Japan? (Letter) Epidemiology 2000; 11: 738

19. Sekikawa A, Kuller LH: Coronary heart disease mortality in the United States among black and white men 35-44 years old by state. CVD Prev 1999; 2: 212-221

20. Sorlie PD, Gold ED: The effect of physician terminology preference on coronary heart disease mortality: An artifact uncovered by the 9th revision ICD. Am J Public Health 1987; 77: 148-152

21. WHO MINICA manual, Version 1.1. Geneva: World Health Organization. 1985; section 4: 9-46

22. Baba S, Ozawa H, Sakai Y, Terao A, Konishi M, Tatara K: Heart Disease Death in a Japanese urban area evaluated by clinical and police records. Circulation 1994; 89: 109-115

23. Naruse Y, Nakagawa H, Yamagami K, Sokejima S, Morikawa Y, Nishijo M, et al: Ischaemic heart disease death in a Japanese rural area evaluated by clinical records. J Epidemiol 1997; 7: 71-76

24. Saito I, Aono H, Ikebe T, Ozawa H, Yamashita T: Trends in fatal ischemic heart disease in Oita City, Japan: Different conclusions based on validated rates versus vital statistics. Cardiovasc Dis Prev 1999; 2: 150-159

25. Saito I, Folsom AR, Aono H, Ozawa H, Ikebe T, Yamashita T: Comparison of fatal coronary heart disease occurrence based on population surveys in Japan and the USA. Int J Epidemiol 2000; 29: $837-844$

26. Traven ND, Kuller LH, Ives DG, Rutan G, Perper JA: Coronary heart disease and sudden death among the 35-44 year age group in Allegeny County, Pennsylvania. Ann Epidemiol 1996; 6: 130-136

27. Japan IDDM Epidemiology Study Group: Lack of regional variation in IDDM risk in Japan. Diabetes Care 1993; 16: 796-800

28. Karvonen M, Tuomilehto J, Libman I, LaPorte R for the World Health Organization DIAMOND Project Group: A review of the recent epidemiological data on the worldwide incidence of Type 1 (insulin-dependent) diabetes mellitus. Diabetologia 1993; 36: $883-$ 892

29. Diabetes Epidemiology Research International Mortality Study Group: International evaluation of cause-specific mortality and 
IDDM. Diabetes Care 1990; 14: 55-60

30. Robertson TL, Kato H, Gordon T, Kagan A, Rhoads GG, Land CE, et al: Epidemiologic studies of coronary heart disease and stroke in Japanese men living in Japan, Hawaii and California: Coronary heart disease risk factors in Japan and Hawaii. Am J Cardiol 1977; 39: 244-249

31. Worth RM, Kato H, Rhoads GG, Kagan K, Syme SL: Epidemiologic studies for coronary heart disease and stroke in Japanese men living in Japan, Hawaii, and California: Mortality. Am J Epidemiol 1975; 102: $481-490$

32. Ueshima H, Iida M, Shimamoto T, Konishi M, Tanigaki M, Doi M, et al: Dietary intake and serum cholesterol level: Their relationship to different lifestyles in several Japanese populations. Circulation 1982; 66: 519-526

33. Ueshima H, Iida M, Shimamoto T, Konishi M, Tanigaki M, Nakanishi N, et al: High-density lipoprotein-cholesterol levels in Japan. JAMA 1982; 247: 1985-1987

34. Dwyer T, Iwane H, Dean K, Odagiri Y, Shimomitsu T, Blizzard L, et al: Differences in HDL cholesterol concentrations in Japanese, American, and Australian children. Circulation 1997; 96: 2830 2836

35. Namekata T, Moore D, Knopp R, Marcovina S, Perrin E, Hughes D, et al: Cholesterol levels among Japanese Americans and other populations: Seattle Nikkei Health Study. J Atheroscler Thromb 1996; 3: $105-113$

36. Nagata C, Takatsuka N, Kurisu Y, Shimizu H: Decreased serum total cholesterol concentration is associated with high intake of soy prod- ucts in Japanese men and women. $J$ Nutr 1998; 128: 209-213

37. Food and Agricultural Organization of the United Nations: Food balance sheets: 1984-1986 average. Rome: FAO, 1991

38. INTERSALT Co-operative Research Group: The INTERSALT Study: An international co-operative study of electrolyte excretion and blood pressure: Further results. J Hum Hypertens 1989; 3: $331-$ 407

39. Iso H, Folsom AR, Wu KK, Finch A, Numger RG, Sato S, et al: Hemostatic variables in Japanese and Caucasian men: Plasma fibrinogen, factor VIIc, and von Willebrand factor and their relations to cardiovascular disease risk factors. Am J Epidemiol 1990; 130: 925-934

40. Berg E, Dyerberg J: Omega-3 fatty acids: Current status in cardiovascular medicine. Drugs 1994; 47: 405-424

41. Law M, Wald N: Why heart disease mortality is low in France: The time lag explanation. BMJ 1999; 318: 1471-1476

42. Iso H, Folsom AR, Sato S, Wu KK, Shimamoto T, Koike K, et al: Plasma fibrinogen and its correlates in Japanese and US population sample. Arterioscler Thromb 1993; 13: 783-790

43. Iso H, Folsom AR, Koike KA, Sato S, Wu KK, Shimamoto T, et al: Antigens of tissue plasminogen activator and plasminogen activator inhibitor 1: Correlates in non-smoking Japanese and Caucasian men and women. Thromb Haemost 1993; 70: 475-480

44. Yano K, Blackwelder WC, Kagan A, Ohoads GG, Cohen JB, Marmot M: Childhood cultural experience and the incidence of coronary heart disease in Hawaii Japanese men. Am J Epidemiol 1979; 109: $440-450$ 